\title{
Credibility: your most important asset
}

\author{
Douglas MacDougall \& Jennifer Conrad \\ Without credibility, everything you say to investors, potential partners or even your employees can be questioned. \\ Here's how to build and retain it.
}

W hat do you think sells your company to the outside world? A promising pipeline? A stellar founding team? A solid intellectual property (IP) portfolio? Those things won't hurt, but credibility may be the most important asset for a startup biotech company (and a public biotech company for that matter). Credibility is your best weapon when facing pipeline delays, regulatory rejections, IP challenges and all the other inevitable issues that are part of a biotech venture. It is the barometer with which others judge you and, by extension, your company. It drives your ability to raise capital, attract partners and hire the best employees.

Credibility engenders belief in your company and all its communications. The temptation to stretch your promises is overwhelming when you are trying to raise capital or secure a partner, especially in today's economy, which has put everyone into survival mode. But credibility is more important than ever in bear markets. In the long run, companies that maintain the best credibility survive while others fail.

\section{Managing expectations}

Of paramount importance to maintaining credibility is effectively managing expectations - those of your shareholders, investors, partners (or potential partners), employees and the myriad other audiences that matter to your business.

A key to this is open and honest communications with your audiences while maintaining perspective on how outsiders may see the company. Acknowledging any weaknesses is a great tool to both build credibility and set expectations. This is done by converting

Douglas MacDougall is president and Jennifer Conrad is senior account executive at MacDougall Biomedical Communications, Wellesley, Massachusetts, USA.

e-mail:dmacdougall@macbiocom.com your weaknesses to milestones or use of proceeds, if you are raising capital. For example, if your weaknesses include that you lack human proof of concept for your lead drug candidate or that your management team lacks certain business or development skills, your milestones and/or use of proceeds portion in any discussion should ideally mention achieving clinical proof of concept and hiring more executives to round out the leadership team. Remember to view your company from the eyes of your investors and the industry as a whole-this might help you understand where your company fits into the overall competitive landscape.

When talking to key audiences about the future of your company, set short-term promises and long-term goals. Remember that to effectively manage expectations, you must always deliver on those short-term promises, so consider them (and the time lines with which you plan to meet them) closely before going on the record.

For long-term goals, note the ever-changing nature of this industry and understand that it is often difficult, if not impossible, to stick to

\section{Box 1 The binary event}

An investigational new drug (IND) application is nothing more than a pile of documents arriving at the US Food and Drug Administration (FDA), and once you make this event public, people will mark their calendars and expect to hear within 30 days that your IND has been approved. This is a classic binary event: what is the upside of announcing an IND filing? What is the downside if you experience setbacks with your IND package? The decision should be a no-brainer. Although an IND filing is certainly reason for a company to throw a celebration for the scientists and regulatory personnel involved in the advancement of the program, it is not the type of event a company should announce to external audiences if they wish to build credibility. Instead, wait until you've received the green light from the FDA, secured institutional review board approval at some of your clinical sites and have begun dosing patients, and then announce the initiation of your phase I trial with the dosing of your first patient. This strategy removes multiple binary events that can come back to bite your credibility.

Here's another example. Many companies are too quick to announce a new addition to their management team. Perhaps it's because the company has been without a CEO for months, or they are about to start clinical trials and have hired a chief medical officer to support their clinical strategy. Even so, it is often impossible to know how the new executive's personality will fit in with those of your existing team members, or how they will feel about the company after spending a bit of time in the trenches. It is not uncommon for an executive to leave a startup soon after being hired. Therefore, companies should wait at least a few weeks after the new person starts before issuing a press release. This 'grace period' often allows you time to determine if the person will work out and if there are any problems that need to be addressed. Otherwise, to issue a press release on the first day of employment (or even before they've officially started with the company) sets you up for yet another potentially embarrassing binary event. If the new CEO or chief medical officer leaves soon after they start and you've already issued a press release, you will have a lot of tedious explaining to do, and it will not reflect well on your company. 


\section{Box 2 Your corporate strategy}

A corporate strategy plays on the strengths of your company's people, science, pipeline and/or technologies. It differs from company to company and is often what makes potential partners and investors decide whether or not you'd be an appropriate partner or a good investment-based upon whether or not your corporate strategy fits in with their partnering or investment strategy. Generally speaking, it tells others just what you intend to do with your company. A common corporate strategy, especially among companies that internally discover and develop their own pipeline, is to out-license to a larger partner after they've achieved proof of concept in phase II. They then use money from these licensing deals to further fuel their early-stage pipeline. If a company with this strategy suddenly begins to in-license later-stage products from other companies, those who were invested in that company's original strategy may question its credibility and rethink their ongoing relationship.

them. You will have to proactively make the necessary adjustments on those longer-term goals. If one appears in jeopardy, relay that information immediately, because one surefire way to damage credibility is to hide a potential missed goal until just before or after the fact. It will cause your audiences to wonder what else is off track within the company and could lead them to doubt other things you say. So if you realize that a goal is no longer attainable and needs to be recalibrated, communicate it right away and reassure the necessary audiences that you have a plan in place to meet the recalibrated goal.

This brings us to the term 'sandbag'. One way to avoid having to recalibrate long-term goals or, worse yet, failing to deliver on those short-term promises is to sandbag your corporate milestones. This means that if you have a clear understanding of your business and company, you may be able to anticipate where delays or hiccups could occur-clinical trial enrollment delays, manufacturing setbacks, financing problems and so on. Once you have determined where possible issues could arise, stretch the time lines in those areas so they are more immune to the ups and downs of the industry. Sandbagging your publicly announced milestones should help you avoid both breaking promises and, as a result, damaging your credibility.

Another key to managing expectations is to minimize publicly announcing 'binary events. These are events key to your company that either will or won't happen-an investigational new drug application (IND) acceptance, a potential partnership, a meeting with the US Food and Drug Administration (FDA), for example-but they can hurt your firm if they don't pan out. Because it's not clear if these events will happen, you should carefully reconsider making public any binary events that you are not required to announce (this is easier for privately held companies). For example, we often counsel our clients not to announce the filing of an IND with the FDA in a press release because little positive can come out of it (Box 1).

And finally, after announcing your shortterm promises and long-term goals to key audiences and making your corporate strategy clear, make sure that every subsequent announcement you make is part of the plan (Box 2). Shareholders don't like to see a company veering off its outlined path or going into new, uncharted territories not previously discussed as part of the strategy. Audiences see credible companies as those who know where they need to go and then follow a logical plan to get there. Therefore, all corporate decisions and announcements should have some sort of definitive tie to 'the plan'. Any announcement about a clinical trial you initiate, IP that is issued or a collaboration you pursue should make sense within the context of what you have told the world you plan to accomplish.

\section{Consistency}

There are many things you should or should not do to build credibility, but one key to achieving it is ensuring that your company is communicating a consistent message to the world (Table 1). Through consistency in all of your communications, your company effectively builds its brand image, which is important not only in the consumer products industry, but also in building a biotech company.

\section{Table 1 Credibility Dos and Don'ts}

Do

Communicate openly with audiences

Acknowledge your weaknesses

Set short-term promises and long-term goals

'Sandbag' corporate milestones

Communicate a consistent message

Develop a crisis plan

Make key people available during a crisis

Draft a publication plan for your science
A strong, consistent brand allows you to control the way investors, partners, the medical community and employees view your company. One mistake many companies make is changing their corporate description based on what is 'hot' at the moment-one year they are focused on genomics, the next on gene therapy and the next on biomarker-based diagnostics. What is wrong with this tactic? In the end, no one truly knows what your company does. How will you know what type of investor would be attracted to your business model? What if you turn off investors who thought they were involved with a pipeline of promising small molecules, and a year later it looks like they are invested in diagnostics? Pharma firms that previously may have been interested in your technology platform may feel that you have abandoned it if you begin to highlight your biomarker services business. Imagine how confusing this change of face might be to the talented scientists you've attracted and to your potential new hires-how will they know if their background is a good fit for this 'new' company? Changing your stripes to meet short-term goals is extremely damaging to your long-term credibility.

\section{Crisis situations}

Although few companies want to face a crisis situation, it is an unavoidable cost of doing business, and how you handle them is a key inflection point in how credible your company appears. Your response to a crisis can hurt or build-yes, build-your company's profile. Bad news doesn't always have to lead to a bad reputation.

First, have a crisis plan in place before disaster strikes, detailing what needs to be done and who needs to do it. Consider the potential crises that your company is subject to-as a biotech company, things such as patient deaths, failed clinical trials, manufacturing problems and the loss of a crucial collaborator are all possibilities - and craft individual plans for each of these scenarios so that you are prepared for whatever may strike. If and when a crisis hits, be proactive rather than reactivetry to speak to your audiences first to inform
Don't

Stretch promises

Fail to maintain an outside perspective of your company Stall on communicating delays or setbacks to key audiences Publicly announce 'binary events'

Change your goals based on what is 'hot' at the moment Be reactive, rather than proactive, during a crisis 
them of what is happening rather than waiting to respond to negative backlash. It is also crucial to make key people available to the media, investors, employees and so forth to address any inquiries or concerns. Make sure all spokespersons are conveying the same message and are communicating consistently with your audiences (another reason why a crisis plan is a smart idea). When answering questions, be up-front and honest, and when you do not know an answer, do not guess or use conjecture-just state the facts that you do know. Let the person know you will find out the answer and get back to them-and follow through. Finally, make sure that the communication lines don't shut down after the day the crisis is announced-continue to make spokespersons available throughout the duration of the event.

\section{Scientific credibility}

Credible science lies at the heart of the biotech industry, so when thinking about your company's credibility, it is also important to pay attention to the credibility of your science. Just as a company can lose its corporate credibility - through mishandling a crisis, not managing expectations and so on-so too can a scientific strategy or approach lose its credibility. From the moment you start your company, you should begin a publication plan for your technology platform and/ or product candidates. This plan should detail which data you plan to have at what points in time, and then which peer-reviewed journals and/or scientific or medical conferences would be appropriate to submit data for potential publication or presentation. Being published in a respected, peer-reviewed journal, or having a poster or abstract accepted at a medical conference central to your field, lends external validation to your science. This third-party endorsement gives your science another layer of credibility that it simply wouldn't get from just you and your colleagues touting it. Third-party validation is something that potential partners, investors and employees pay attention to and seek out when deciding who to collaborate with, invest in or work for.
When developing the publication plan for your pipeline, make sure that it is continuous. It is important to maintain a consistent level of published scientific data over the course of a company's life, particularly when the company is young and needs to build its profile and credibility. Early-stage startups often have large time gaps in their news flow when no clinical trials are being initiated or no new data are being announced-so scientific publications and presentations fill in those otherwise empty news gaps.

\section{Conclusions}

The biotech industry has a very unique business model that requires companies to raise hundreds of millions of dollars over a decade or more to advance and sustain their products before they gain the ability to generate a consistent revenue stream. The most quantifiable measurement of success in almost any business is revenue and/or earnings growth. In the absence of these measures, biotech companies have to depend on meeting multiple milestones and attracting third-party endorsements to quantify success. Credibility is the key to selling your success, and in this new age of instant communication through the Internet, your reputation is global. 